\title{
Use of consensus development to establish national research priorities in critical care
}

\author{
Keryn Vella, Caroline Goldfrad, Kathy Rowan, Julian Bion, Nick Black
}

\section{Intensive Care \\ National Audit and \\ Research Centre, \\ London \\ WC1H 9HR \\ Keryn Vella \\ research fellow \\ Caroline Goldfrad \\ statistician \\ Kathy Rowan \\ scientific director \\ Department of \\ Anaesthesia and \\ Intensive Care \\ University of \\ Birmingham, \\ Birmingham \\ B15 2TH \\ Julian Bion \\ reader in intensive \\ care medicine \\ Department of \\ Public Health and \\ Policy, London \\ School of Hygiene \\ and Tropical \\ Medicine, London \\ WC1E 7HT \\ Nick Black \\ professor \\ Correspondence to: \\ N Black \\ n.black@ \\ Ishtm.ac.uk}

BMJ 2000;320:976-80

\begin{abstract}
Objectives To test the feasibility of using a nominal group technique to establish clinical and health services research priorities in critical care and to test the representativeness of the group's views.

Design Generation of topics by means of a national survey; a nominal group technique to establish the level of consensus; a survey to test the representativeness of the results.

Setting United Kingdom and Republic of Ireland. Subjects Nominal group composed of 10 doctors (8 consultants, 2 trainees) and 2 nurses.

Main outcome measure Level of support (median) and level of agreement (mean absolute deviation from the median) derived from a 9 point Likert scale. Results Of the 325 intensive care units approached, $187(58 \%)$ responded, providing about 1000 suggestions for research. Of the 106 most frequently suggested topics considered by the nominal group, 37 attracted strong support, 48 moderate support and 21 weak support. There was more agreement after the group had met-overall mean of the mean absolute deviations from the median fell from 1.41 to 1.26 . The group's views represented the views of the wider community of critical care staff $(\mathrm{r}=0.73, \mathrm{P}<0.01)$. There was no significant difference in the views of staff from teaching or from non-teaching hospitals. Of the 37 topics that attracted the strongest support, 24 were concerned with organisational aspects of critical care and only 13 with technology assessment or clinical research.
\end{abstract}

Conclusions A nominal group technique is feasible and reliable for determining research priorities among clinicians. This approach is more democratic and transparent than the traditional methods used by research funding bodies. The results suggest that clinicians perceive research into the best ways of delivering and organising services as a high priority.

\section{Introduction}

The need to involve as many legitimate stakeholders as possible in the identification and prioritisation of research topics is increasingly being recognised. Not only might such a strategy ensure that the interests of all relevant people are considered, it might also increase ownership of the ensuing research and, perhaps, the likelihood of the results influencing clinical practice and policy. The more groups and individuals involved, however, the greater the potential difficulty in prioritising suggestions. Informal methods, such as committees, risk being dominated by the more powerful members. In contrast, formal methods of consensus development provide a means of managing group decision making so that all participants have the same influence on the outcome. ${ }^{1}$ These methods have been used to prioritise research, but, apart from occupational medicine ${ }^{23}$ and haematology, ${ }^{4}$ their use has been confined to nursing ${ }^{5-10}$ and chiropractic. ${ }^{11}$

Our primary objectives were to test the feasibility of using a nominal group technique and to establish priorities for clinical and health services research in critical (intensive and high dependency) care based on the views of a small selected group of the principal clinicians involved-doctors and nurses. The secondary objectives were to determine the extent to which priorities differ between staff from units based in teaching and non-teaching hospitals, to investigate the impact of the nominal group technique on participants' initial views, and to assess whether the views of such a small selected panel are representative of practising clinicians in general. This last issue has been investigated only once before in the health field-in the context of guidelines for coronary angiography. ${ }^{12}$

\section{Methods}

\section{Generation and categorisation of topics}

We sought potential research topics from all 325 intensive care units in the United Kingdom and Republic of Ireland in July 1998. We asked the clinical director (or lead consultant) and nurse manager of each adult unit to suggest up to 10 research topics (on intensive care organisation, clinical practice, and outcomes) that they considered the most important. They were encouraged to discuss ideas with their unit colleagues, particularly more junior ones. As respondents could remain anonymous, reminders could not be sent to non-respondents. After exclusion of suggestions not containing a hypothesis (for example, "how many units have more than six beds?"), an experienced clinician (JB) categorised the rest according to 15 domains using the predominant theme of the topic. The 100 most frequently suggested topics were selected-the maximum deemed possible for the nominal group to consider in a single day.

\section{Composition of nominal group}

The members of the nominal group were selected from people that we knew to be interested in research in intensive care in the United Kingdom and Ireland. The composition of the group was intended to reflect the diversity of clinician involvement in critical care and the level of influence of each category on critical care policy and practice. Of the 12 people invited, only one declined to participate; he was replaced. For the 325 UK and Irish intensive care units, the 12 participants reflected the professions (10 doctors, 2 nurses); grade of doctor (8 consultants, 2 trainees); geographic distribution (5 from London and the south east, 2 from the south west and Wales, 4 from the Midlands and East Anglia, 1 from northern England and Scotland); and hospital status (5 teaching, 7 nonteaching). 


\section{Nominal group process}

We sent participants a first round questionnaire about the 100 suggested research topics, asking them to indicate their personal level of support for each topic on a Likert scale of 1 to $9(1=$ no support, $5=$ moderate support, $9=$ strong support). Replies from the 12 participants were collated, and the distribution of ratings for each topic was displayed on the line below the Likert scale in the second round questionnaire. These questionnaires, personalised such that each participant also had their own first round ratings indicated, were distributed to participants when they attended a one day group meeting in October 1998.

The meeting was facilitated by NB, who had experience of nominal group techniques. The group had to explore the reasons for any differences in ratings and re-rate all 100 topics. This was an opportunity to reconsider their initial rating in the light of other participants' views. They were under no pressure to achieve consensus, and all ratings were made privately. The facilitator tried to ensure that all participants had an opportunity to contribute. Two observers (JB, KR) kept a non-attributable written record of the main points of the discussion. When differences in first round ratings seemed to have resulted partly from ambiguity in the wording of the topic, the group agreed a revised wording before making their second round rating.

For each topic, the level of group support for a topic hypothesis was indicated by the median and the level of agreement within the group by the mean absolute deviation from the median. Topics were ranked according to the medians. Medians of 7-9 were defined as strong support, 4-6.5 as moderate, and 1-3.5 as weak. The level of agreement was categorised according to thirds of the mean absolute deviation from the median (low >1.41, moderate 1.08-1.41, high < 1.08). Any change between the first and the second round indicated the impact of the nominal group meeting in promoting consensus. The significance of any change in rank order was tested with Wilcoxon's signed ranks test, and any association between the level of support and the degree of consensus for topics was tested with the $\chi^{2}$ test.

\section{Assessment of representativeness}

To assess the representativeness of the group's views, we sent a questionnaire to the 313 intensive care units that were not represented by members of the nominal group. The questionnaire included 30 of the topics that the nominal group had considered, 10 of which had attracted strong support, 10 moderate support, and 10 weak support. The topics were mixed up, and the recipients were not told of the basis of the topic selection. The questionnaire layout and the rating scale were similar to those used with the nominal group. As before, the level of support (median) and of agreement (mean absolute deviation from the median) for each topic was calculated. The representativeness of the group's view was assessed by the level of association with the survey finding (Pearson correlation coefficient) and the level of agreement ( $\kappa$ statistic). Finally, responses from the staff of teaching (university or university affiliated) hospitals were compared with those from non-teaching hospitals.

\section{Results}

Generation and categorisation of topics

Of the 325 intensive care units approached, 187 (58\%) responded, providing about 1000 suggestions for research. Many topics recurred, which facilitated the identification of the most frequently cited ones. The 15 categories each contained four to six topics, apart from the "organ system support and treatment" category, which included 28 topics. Table 1 shows some examples.

Table 1 Categories and examples of research questions most frequently suggested by staff of 187 intensive care units

\begin{tabular}{|c|c|}
\hline Category & Examples of topics \\
\hline Structure and resources & $\begin{array}{l}\text { Do small and large intensive care units have different outcomes? Does regionalisation of paediatric intensive care } \\
\text { improve outcome? }\end{array}$ \\
\hline High dependency care & $\begin{array}{l}\text { Is the presence of a high dependency unit associated with improved hospital outcomes? Do such units deskill ward } \\
\text { nurses? }\end{array}$ \\
\hline Nursing practice & $\begin{array}{l}\text { Does skill mix affect patient outcomes? Do children nursed in paediatric intensive care units have better quality of } \\
\text { care than those nursed in general units? }\end{array}$ \\
\hline Transfers & $\begin{array}{l}\text { Do specialised transport teams have better outcomes than non-specialist teams? Do transferred patients have poorer } \\
\text { outcomes than non-transferred patients? }\end{array}$ \\
\hline Process of care and clinical practice & Does multidisciplinary team working affect outcomes? Are pressure relieving mattresses cost effective? \\
\hline $\begin{array}{l}\text { Admission and discharge, criteria, protocols, } \\
\text { and guidelines }\end{array}$ & $\begin{array}{l}\text { Does the presence of guidelines or protocols influence outcomes of intensive care units? Does a nurse led protocol } \\
\text { for extubation result in a shorter period of ventilatory support? }\end{array}$ \\
\hline Monitoring & Do pulmonary artery catheters change outcomes? Is gastric tonometry useful? \\
\hline Organ system support and treatment & Does early enteral feeding improve outcome? Are steroids effective in the acute respiratory distress syndrome? \\
\hline $\begin{array}{l}\text { Training, information, and data handling and } \\
\text { education }\end{array}$ & $\begin{array}{l}\text { Do postmortem examinations in intensive care patients alter practice? Would the training of medical students be } \\
\text { improved if they worked with intensive care nurses? }\end{array}$ \\
\hline Audit; quality and risk assessment & What outcome measures should be used in intensive care units? Are long term outcomes worse for elderly people? \\
\hline Ethics & $\begin{array}{l}\text { Would risk management be improved if nursing staff wrote directly in medical notes? Should patients who have had } \\
\text { a cardiac arrest and are unconscious be admitted to an intensive care unit? }\end{array}$ \\
\hline
\end{tabular}

${ }^{*}$ Clinics for following up the survivors of intensive care. 
Table 2 Examples of topics with strong (median 7-9), moderate (median 4-6.5), or weak (median 1-3.5) support in final rating. Values are medians (mean absolute deviation from median)

\begin{tabular}{lcc} 
Topic & Initial rating & Final rating \\
\hline Does regionalisation of paediatric intensive care improve outcome? & $7.5(1.50)$ & $8.5(1.08)$ \\
\hline $\begin{array}{l}\text { Do district general hospitals' intensive care units perform as well as } \\
\text { major or university centres? }\end{array}$ & $7.5(2.17)$ & $8.0(1.92)$ \\
\hline Do pulmonary artery catheters affect patient outcomes? & $8.0(1.17)$ & $8.0(1.17)$ \\
\hline Does the presence of an advanced nurse practitioner affect outcomes? & $5.0(1.17)$ & $5.0(1.00)$ \\
\hline Is gastric tonometry useful? & $5.0(1.25)$ & $5.0(0.92)$ \\
\hline What is the best vasoactive drug regimen for septic shock? & $5.0(1.67)$ & $4.5(1.83)$ \\
\hline Do steroids affect outcome in head injury? & $3.5(1.50)$ & $3.0(1.08)$ \\
\hline Should relatives be present during resuscitation attempts? & $3.0(0.75)$ & $2.0(0.83)$ \\
\hline Do physician led intensive care units have better outcomes than & $2.0(0.92)$ & $1.0(0.58)$
\end{tabular}

Table 3 Comparison of nominal group's views ( $n=12$ ) with views obtained by national survey $(n=244)$. Values are medians (mean absolute deviation from median)

\begin{tabular}{|c|c|c|}
\hline Topic & $\begin{array}{c}\text { Nominal } \\
\text { group }\end{array}$ & Survey \\
\hline Does regionalisation of paediatric intensive care improve outcome? & $8.5(1.08)$ & $7.0(1.76)$ \\
\hline Does early intervention alter outcomes of intensive care units? & $8.0(0.67)$ & $8.0(1.03)$ \\
\hline Does early enteral feeding improve outcome? & $8.0(1.00)$ & $8.0(1.19)$ \\
\hline Does the nurse to patient ratio affect patient outcomes? & $8.0(1.08)$ & $8.0(1.46)$ \\
\hline Do pulmonary artery catheters affect patient outcomes? & $8.0(1.17)$ & $7.0(1.85)$ \\
\hline $\begin{array}{l}\text { Do patients admitted to high dependency units have better outcomes than if they } \\
\text { are admitted to general wards? }\end{array}$ & $8.0(1.17)$ & $8.0(1.11)$ \\
\hline $\begin{array}{l}\text { Does interhospital transfer resulting from a shortage of available beds affect } \\
\text { patient outcomes? }\end{array}$ & $8.0(1.25)$ & $8.0(1.34)$ \\
\hline Does optimisation of perioperative care of surgical patients improve outcome? & $8.0(1.25)$ & $7.0(1.45)$ \\
\hline $\begin{array}{l}\text { Do district general hospitals' intensive care units perform as well as major or } \\
\text { university centres? }\end{array}$ & $8.0(1.92)$ & $7.0(1.64)$ \\
\hline $\begin{array}{l}\text { Can we make meaningful comparisons of the performance of intensive care units } \\
\text { on the basis of standardised mortality ratios? }\end{array}$ & $7.5(1.17)$ & $6.0(1.94)$ \\
\hline Are pressure relieving mattresses cost effective? & $6.0(1.42)$ & $6.0(2.10)$ \\
\hline Do psychotropics improve recovery of long stay intensive care patients? & $5.5(0.92)$ & $6.0(1.73)$ \\
\hline Does early tracheostomy produce better outcomes than late tracheostomy? & $5.5(2.08)$ & $7.0(1.52)$ \\
\hline Is gastric tonometry useful? & $5.0(0.92)$ & $5.0(1.89)$ \\
\hline Does the presence of an advanced nurse practitioner affect the outcomes? & $5.0(1.00)$ & $6.0(1.91)$ \\
\hline $\begin{array}{l}\text { Is there a relation between the incidence of nosocomial infections in intensive } \\
\text { care units and staffing ratios? }\end{array}$ & $5.0(1.25)$ & $7.0(1.68)$ \\
\hline Do the social characteristics of patients or medical staff influence treatment intensity? & $5.0(1.58)$ & $5.0(2.13)$ \\
\hline $\begin{array}{l}\text { Do units with a clinical educator have fewer difficulties in recruiting and retaining } \\
\text { nurses? }\end{array}$ & $5.0(2.00)$ & $7.0(1.95)$ \\
\hline Do strict bed management policies affect overall outcomes and resource use? & $5.0(2.17)$ & $6.0(1.74)$ \\
\hline $\begin{array}{l}\text { Can scoring patients before allocation to an intensive care unit improve patient } \\
\text { selection? }\end{array}$ & $4.0(1.67)$ & $6.0(1.90)$ \\
\hline Would risk management be improved if nursing staff wrote directly in medical notes? & $2.5(1.17)$ & $5.0(2.25)$ \\
\hline Do visitors affect patient outcomes? & $2.5(1.42)$ & $5.0(1.95)$ \\
\hline Does low dose dopamine alter renal outcomes? & $2.5(1.50)$ & $6.0(2.08)$ \\
\hline Should relatives be present during resuscitation attempts? & $2.0(0.83)$ & $5.0(2.18)$ \\
\hline Are patients more likely to die on certain days of the week, and, if so, why? & $2.0(1.00)$ & $3.0(2.00)$ \\
\hline Does routine replacement of central venous pressure catheters reduce infection rates? & $2.0(1.25)$ & $6.0(2.09)$ \\
\hline $\begin{array}{l}\text { Should patients who have had a cardiac arrest and are unconscious be admitted to } \\
\text { intensive care units? }\end{array}$ & $2.0(1.33)$ & $5.0(2.11)$ \\
\hline Does severity scoring influence clinical practice in individual patient management? & $1.0(0.25)$ & $5.0(1.86)$ \\
\hline $\begin{array}{l}\text { Do physician led intensive care units have better outcomes than anaesthetist led } \\
\text { units? }\end{array}$ & $1.0(0.58)$ & $5.0(2.09)$ \\
\hline Should nurses in intensive care units be involved in decisions to withdraw treatment? & $1.0(1.25)$ & $7.0(1.98)$ \\
\hline
\end{tabular}

\section{Nominal group's level of support}

At the group meeting, discussion of the 100 most frequently suggested topics led to several changes to the topics. It was apparent that the wording of six topics were ambiguous because they contained two independent issues (for example, "Does skill mix and staff/ patient ratio affect sickness rates amongst intensive care unit nursing staff?"); such topics were split into two, resulting in a total of 106 topics. In three topics, terms were altered to clarify or broaden the meaning ("antidepressants" became "psychotropics," "inotropic" became "vasoactive," and "staffed beds" became "available beds"). As a result, direct comparisons of the group's initial ratings and their meeting ratings had to be confined to the 91 unmodified topics.

Of the 106 topics, 37 attracted strong support (final median 7-9), 48 moderate support (median 4-6.5), and 21 weak support (median 1-3.5). Table 2 shows examples. The level of agreement within the group varied by topic, as indicated by the mean absolute deviation from the median. The level of support for a topic was significantly positively associated with the level of group agreement $\left(\chi^{2}=13.4, \mathrm{P}=0.01\right)$. Of the 37 topics attracting strong support, 24 related to identifying the organisational features of critical care that are likely to improve patient outcomes.

\section{Effect of nominal group technique on rank order and level of consensus}

The effect of the group meeting was to polarise views more-the number of topics with moderate support declined (66 to 39) while the number with strong or weak support increased (19 to 32 and 6 to 20 respectively). Overall, the category of level of support did not alter for 62 topics, decreased for 15, and increased for 14. Although the rank order of the 91 topics changed, the change was not significant (Wilcoxon signed ranks test, $\mathrm{z}=-0.27 ; \mathrm{P}=0.98$ ).

There was more agreement after the meeting than before. The overall mean of mean absolute deviation from the median for all 91 topics fell from 1.41 to 1.26. A high level of agreement was achieved for 25 topics at the meeting (compared with 18 beforehand), and the number of topics with low agreement fell from 51 to 30. While 48 topics did not change much, 21 shifted from low to moderate agreement and 13 from low or moderate to high agreement. In contrast, the level of agreement over 9 topics fell as a result of the meeting.

Representativeness of nominal group's judgment A $78 \%$ response rate $(244 / 313)$ was achieved in the survey to assess the representativeness of the group's judgment. Although the rank order of the level of support for topics was similar (Mann-Whitney U test, $\mathrm{z}=337$, $\mathrm{P}=0.09)$ and the level of association of ratings was highly significant $(\mathrm{r}=0.73, \mathrm{P}<0.01)$, the actual ratings were generally much higher among the survey respondents (table 3). This was reflected in the low level of agreement between the group and the survey ratings $(\kappa=0.15)$. Lower levels of consensus existed among the 244 survey respondents than in the nominal group. In the survey, high agreement was achieved for only one of the 30 topics compared with nine by the group, and, conversely, for 26 of the 30 topics there was only low agreement among the survey respondents. The principal reason for the low level of agreement between the group and the survey respondents was that the latter had assumed that all 30 topics had considerable support from the group (probably because when we were originally seeking topic suggestions we wrote, "we will be circulating the most 'popular' research questions for you to help us prioritise").

Views of teaching and non-teaching hospital staff Of the 244 respondents to the survey, 58 were based in teaching and 186 in non-teaching hospitals. There was 
no difference in the median of the median scores (6.0) for the 30 topics between these two groups of staff, and the rank order of topics was similar (Mann-Whitney U test, $\mathrm{z}=382.5 ; \mathrm{P}=0.302$ ).

\section{Discussion}

Feasibility of formal consensus development We have demonstrated the feasibility of using a formal consensus development method for establishing clinical and health services research priorities in a specific clinical area. Participation by the relevant clinical community was good ( $57 \%$ without use of reminders), suggesting a high level of interest in identifying research topics. Although the high response meant that a large number of suggestions were received (over 1000 ), there was sufficient commonality to allow us identification of $100 \mathrm{key}$ issues. This commitment among staff was also reflected in the high acceptance rate for participating in the nominal group (11 out of the original 12 invited) and in the response to the final survey $(78 \%)$.

\section{Clinicians' views of research priorities}

We have established what clinicians' views of clinical and health services research priorities are. Topics related to research into the organisation and delivery of critical care dominated, with less support for evaluation of specific healthcare technologies such as investigations and treatments. Most of the topics that attracted strong support related to organisational features of critical care likely to improve patient outcomes. This may explain why we found little difference in the views of staff from teaching and non-teaching hospitals.

\section{Value of nominal group meeting}

In terms of the rank order of support for suggested topics, the meeting had little impact. But it did serve to increase the level of agreement between group members. It also tended to polarise the topics-27 of the 66 topics that had moderate support in the initial ratings shifted to strong or weak support following discussion. Associated with this phenomenon was the observation that the greater the level of support for a topic, the more agreement there was in the group. The meeting also provided insights into the reasons for a lack of agreement where this arose.

We also have shown that the views of a small nominal group can represent those of the wider community from which they are drawn. This is consistent with the only other evidence from the health sector, which showed that in the United States the views of nine family physicians, cardiologists, and cardiac surgeons on the appropriate use of coronary angiography were consistent with the views of 1058 colleagues. ${ }^{12}$ We too found high levels of association and a similar ranking of topics.

\section{Shortcomings of study design}

Firstly, some of the initial lack of agreement between group members arose because of ambiguity in the wording of topics. This highlights the need for great care in the preparation of questionnaires, including a pilot phase to check for face validity. This will not guarantee the avoidance of all problems but would reduce the likelihood.

\section{What is already known on this topic}

Formal consensus development methods have rarely been used to establish national research priorities in medicine, partly because their feasibility and reliability is uncertain

\section{What this study adds}

In critical care, clinicians can generate and then rate the importance of research topics using a nominal group technique

The group's views represented the views of the wider community of critical care staff, suggesting that the approach could be used to improve the transparency and democracy of decision making by research funding bodies

Secondly, we created some confusion in the minds of the respondents to the final survey by inadvertently indicating in our earlier communication that we would be sending them the "most 'popular' research questions" to rank. With this expectation, some respondents seemed reluctant to assign low scores to topics; a quarter $(62 / 244)$ rated over $90 \%$ of topics with a score of 5 or more. Despite this influence, the ranking of topics was similar to that of the nominal group.

Thirdly, we confined this exercise to the two principal clinical groups with a strong, clear interest in critical care-namely, doctors and nurses. We ignored the views of other stakeholders, such as therapists, technicians, patients, relatives, and staff from other medical specialties. The results might have been different if the views of these other groups had been considered. It is also important to recognise that this study has identified the most commonly perceived priorities for research. These may not be the most important for improving the quality of critical care.

\section{Implications}

This study has implications both for the use of consensus development methods and for research in critical care. We encourage the approach described here in other areas of health care, not only as a means of identifying research priorities in a structured and transparent way but also to establish whether the method is equally robust when tackling very different issues, such as long term care or community services. Although there have been some previous applications of consensus development methods, they have mostly used Delphi surveys 235-7910 or informal mechanisms for deriving group judgments.

We encourage researchers in critical care to focus on the topics that have the widest support and to use that fact when approaching research funding bodies. We also encourage funders to use the results of exercises such as the one described here to shape and influence their commissioning of research. Studies that have the widespread support of the key clinical groups are more likely to gain cooperation and participation in their execution and, maybe, increase the likelihood of any research findings being taken up in clinical practice and policy. The approach described here also has the advantage of being systematic and transparent, unlike the usual means used by funding bodies to prioritise their 
needs. However, greater involvement of stakeholders and the application of clear method have a cost. We estimate that the whole process of organising, running, and analysing the nominal group cost about $£ 10000$ (including about $£ 5000$ for the time of all the clinical participants). We believe that the clear benefits of the approach make this highly cost effective.

We thank all staff from intensive care units who responded to the initial request for topics and the final survey, and members of the nominal group (Drs Geoff Bellingan, Ruth Endacott, Chris Garrard, Cameron Howie, Andy Padkin, Saxon Ridley, Alasdair Short, Sue Sinclair, Mervyn Singer, Carl Waldmann, and David Watson, and Mrs Sue Baker).

Contributors: KV administered data collection and data entry; CG advised on and carried out data analysis and commented on the paper; KR contributed to the design of the study, coordinated the research, and commented on the paper; JB initiated the study, contributed to its design, analysed the initial topic suggestions, recruited the group members, and commented on the paper; and NB contributed to the study design, facilitated the nominal group, wrote the paper, and is its guarantor.

Funding: Research and development directorate of the West Midlands regional office of the NHS Executive.

Competing interests: None declared.
1 Black NA, Murphy M, Lamping D, McKee M, Sanderson C, Askham J, et al. Consensus development methods: a review of best practice in creating clinical guidelines. J Health Serv Res Policy 1999;4:236-48.

2 Van der Beek AJ, Frings-Dresen MH, van Dijk FJ, Houtman IL. Priorities in occupational health research: a Delphi study in the Netherlands. Occup Envirom Med 1997;54:504-10.

3 Harrington JM, Calvert IA. Research priorities in occupational medicine: a survey of United Kingdom personnel managers. Occup Environ Med 1996;53:642-4.

4 Brittenham GM, Franks AL, Rickles FR. Research priorities in hereditary hemochromatosis. Ann Intern Med 1998;129:993-6.

5 Lindeman CA. Delphi survey of priorities in clinical nursing research. Nursing Res 1975;24:434-41.

6 Bond S, Bond J. A Delphi survey of clinical nursing research priorities. J Adv Nursing 1982:7:565-75.

7 Schmidt K, Montgomery LA, Bruene D, Kennedy M. Determining research priorities in pediatric nursing: a Delphi study. J Pediatr Nurs 1997;12:201-7.

8 Thomas B. Using nominal group technique to identify researchable problems. J Nurs Educ 1983;22:335-7.

9 Sedlak C, Ross D, Arslanian C, Taggart H. Orthopaedic nursing research priorities: a replication and extension. Orthop Nurs 1998:17:51-8

10 Rudy SF. A review of Delphi surveys conducted to establish research priorities by speciality nursing organisations from 1985-1995. Otolaryngol Head Neck Nurs 1996;14:16-24

11 Mootz RD, Coulter ID, Hansen DT. Health services research related to chiropractic: review and recommendations for research prioritisation by the chiropractic profession. J Manipulative Physiol Ther 1997;20:201-17.

12 Ayanian JZ, Landrum MB, Normand S-LT, Guadagnoli E, McNeil BJ. Rating the appropriateness of coronary angiography-do practising physicians agree with an expert panel and with each other? $N$ Engl J Med physicians agree with

(Accepted 13 December 1999)

\title{
Ethnicity and prescription of analgesia in an accident and emergency department: cross sectional study
}

\author{
Desiree M A Choi, Paul Yate, Tim Coats, Paul Kalinda, Elizabeth A Paul
}

Barts and the

London NHS Trust, Department of Anaesthetics, Royal London Hospital, London E1 1BB

Desiree M A Choi specialist registrar

Paul Yate

consultant

Accident and

Emergency

Department, Royal

London Hospital

Tim Coats

consultant

Clinical

Effectiveness Unit,

Royal London

Hospital

Paul Kalinda

manager

St Bartholomew's

and the Royal

London School of

Medicine and

Dentistry,

Department of

Environmental and

Preventive

Medicine, London

E1 2AD

Elizabeth A Paul

lecturer in medical

statistics

Correspondence to:

$P$ Yate

Pyate@aol.com

BMJ 2000;320:980-1
Ethnicity can be a risk factor for inadequate administration of analgesia in accident and emergency departments. ${ }^{1}$ In an emergency department in Los Angeles, United States, Hispanic patients were twice as likely as non-Hispanic white patients to receive no analgesia.

Around the Royal London Hospital, over 25\% of the population is Bangladeshi, and about $60 \%$ of the population is white (East London and City Health Authority, unpublished estimates for 1997). We studied prescription of analgesia for patients presenting with isolated long bone fractures to investigate whether Bangladeshi patients are as likely to receive analgesia as white patients. The local ethics committee approved the study.

\section{Patients and methods}

We reviewed the notes of patients aged $15-55$ years in whom an isolated long bone fracture had been diagnosed between 1 July 1997 and 30 June 1998. Patients were excluded if the injury had occurred more than six hours before the time of presentation, or if any intoxication with alcohol or drugs or alteration in mental status was observed. Administration of analgesics (dichotomised as any or none), ethnicity, age, sex, mechanism of injury, specific bone fractured, need for reduction of the fracture, and admission to hospital were recorded. Reception staff in the accident and emergency department recorded ethnic category at registration in accordance with categories used in the census. Analysis of variance and the independent samples $t$ test were used for age comparisons and the $\chi^{2}$ test was used for associations between categorical variables.

\section{Results}

Of 307 subjects, $224(73 \%)$ patients were white and 42 (14\%) were Bangladeshi. Eighteen patients $(6 \%)$ were of other ethnic background. The ethnicity of $23(7 \%)$ patients was not recorded. The table shows age, sex, characteristics of injury, and prescription of analgesics for each ethnic group. Overall, $243(79.1 \%)$ patients received analgesia for long bone fractures. Of the white patients, $175(78.5 \%)$ received analgesia, compared with $34(81 \%)$ of the Bangladeshi patients, a difference of 2.5 percentage points $(95 \%$ confidence interval -10.5 to 15.5$)$.

The groups were similar in the mechanism of the injury, the fractured bone, admission to hospital, or proportion of patients needing reduction. Although the proportion of male patients was slightly higher in the Bangladeshi group, the difference was not significant, and within each ethnic subgroup male and female patients had similar rates of analgesia (table). The Bangladeshi patients were on average eight years younger than the white patients $(\mathrm{P}<0.05)$. But mean age did not differ between patients who received analgesia and those who did not, neither overall nor within each ethnic subgroup.

\section{Comment}

We found no difference between the proportions of Bangladeshi and white patients who received analgesia. Seventy nine per cent of patients with isolated long bone fractures received analgesia, which is consistent with a previous report. ${ }^{1}$ We did not directly assess whether the injuries in each ethnic group were equally painful, but 